\title{
A possible fossil paralarva (Cephalopoda: Coleoidea) from the Solnhofen Lithographic Limestones (Upper Jurassic, southern Germany)
}

\author{
Joachim T. Haug, Isabelle Kruta, and Carolin Haug
}

\begin{abstract}
We describe a possible fragmentary gladius of a paralarval cephalopod from the Solnhofen Lithographic Limestones, southern Germany (Upper Jurassic, Lower Tithonian). The specimen is $3 \mathrm{~mm}$ long and leaf-shaped, representing mainly the median field of the gladius. Faint remains indicate the former positions of the lateral fields. The median line is marked by a sharp keel. On the posterior end there is a pear-shaped structure. Anteriorly a kite-shaped area is ornamented with small pits. The principle morphology resembles, for example, certain trachyteuthidids, based on shape, presence of a keel and an ornamented anterior kite-shaped region. Also resemblances of certain muensterellid characters are pointed out. The special morphology of the here described specimen is interpreted as ontogenetically caused. This together with its small size makes a paralarval status of the specimen possible, although we cannot provide the necessary ecological evidence for this assignment. A clear ascription to any systematic group is hindered by the fact that there is no comparable material of similarly small size available.
\end{abstract}

Joachim T. Haug, University of Greifswald, Zoological Institute and Museum, Department of Cytology and Evolutionary Biology, Soldmannstr. 23, 17487 Greifswald, Germany

joachim.haug@palaeo-evo-devo.info

Isabelle Kruta, Yale University, Department of Geology and Geophysics, PO Box 208109, New Haven

Connecticut 06520-8109, USA and American Museum of Natural History, Division of Paleontology

(Invertebrates), New York, New York 10024, USA

isabelle.kruta@yale.edu

Carolin Haug, University of Greifswald, Zoological Institute and Museum, Department of Cytology and

Evolutionary Biology, Soldmannstr. 23, 17487 Greifswald, Germany

carolin.haug@palaeo-evo-devo.info

Keywords: palaeo-evo-devo; cephalopods; gladius; fossilized ontogenies; larva; fluorescence microscopy 


\section{INTRODUCTION}

The hatching stage of a metazoan that differs significantly in morphology, behavior or other aspects from the adult is termed larva in many different taxa. The term is treated differently in the literature, varying in the exact criteria that need to be fulfilled to apply it (see, for example, discussions in Hickman, 1999; Young, 2002; Minelli, 2003). For cephalopod molluscs this dispute has partly been avoided by introducing the term paralarva for the early developmental phase that follows hatching and resembles the adult in gross morphology, but differs in its ecological niche (Young and Harman, 1988); paralarvae are planktonic. This specialised early life stage is found in some, but not all modern cephalopods. As for many metazoan taxa, the ontogeny of cephalopods is an important field of research (e.g., Tsuchiya and Okutani, 1991; Boletzky, 2003; O'Shea et al., 2007), including studies of paralarvae (Tsuchiya et al., 1991; Vecchione et al., 1992, 2001; Haimovici et al., 2002).

Investigating the ontogeny of fossil representatives of Cephalopoda is, as for any other taxon, more complex and restricted in many aspects as compared to investigating the ontogeny of extant cephalopods. For fossil cephalopods the ontogeny of a certain species is usually reconstructed by investigating the shell, as this is what remains of the animal, the soft body parts being only preserved in exceptional cases (e.g., Weitschat, 1986; Fuchs et al., 2009; Kruta et al., 2011).

Coleoid cephalopods possess an interior shell or remains of it that gained different names in different subtaxa. For coleoids with a so-called gladius, growth lines on the latter are used for reconstructing the life histories in extant species (Perez and O'Dor, 2000), but these growth lines also yield significant information in fossil coleoids (Fuchs et al., 2009). Thus, aspects of both extant and fossil ontogenies of Cephalopoda can be reconstructed based on few or even a single mature specimen.

With such an approach many aspects of the ontogeny of a fossil cephalopod can be accessed. Yet, differences in the total shape of the gladius can be difficult to infer exclusively from the growth marks of a single mature specimen. Although ontogenetic changes of the coleoid gladius are generally considered to be minor (Boletzky, 2003), in the few examples in which actual gladii of different growth stages of the same species have been depicted in detail, their shapes appear to differ quite significantly (Tsuchiya and Okutani, 1991; O'Shea et al., 2007; Figure 1). Identifying such dif-
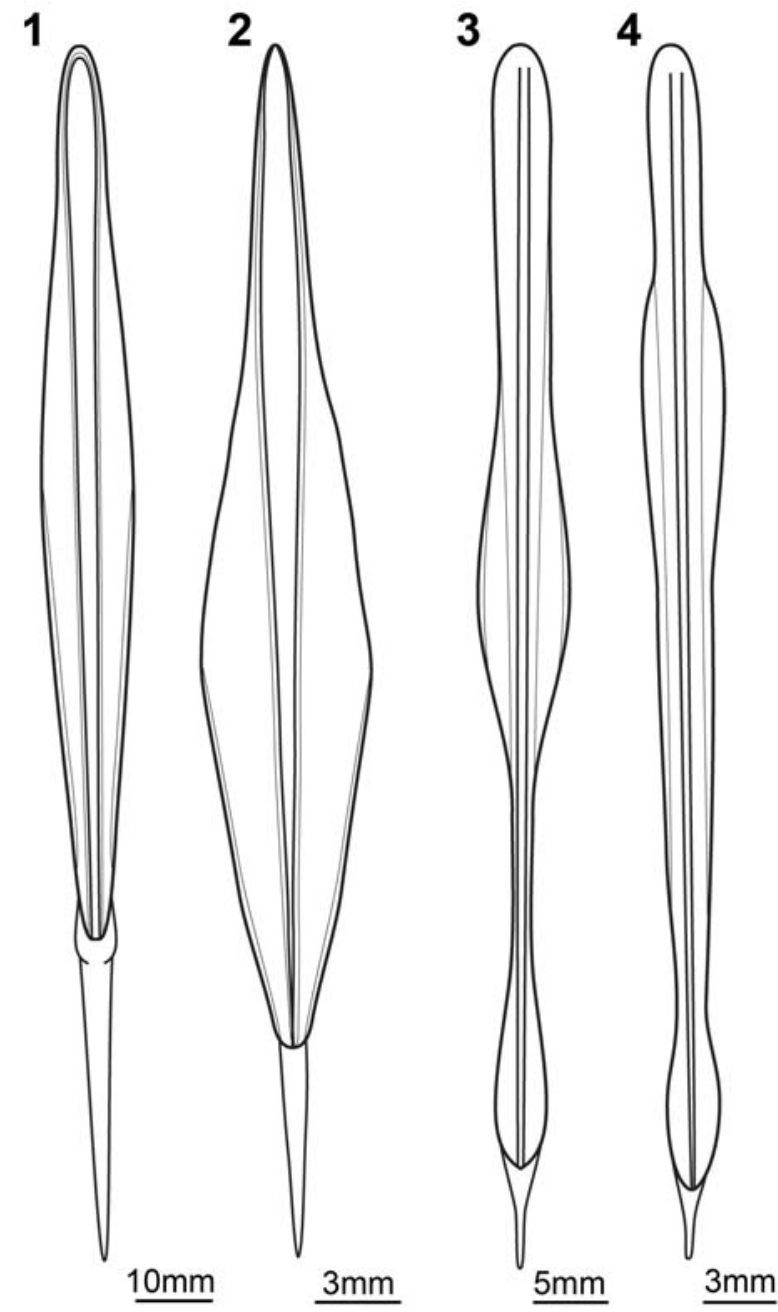

FIGURE 1. Comparison of gladius shapes between older $(1.1,1.3)$ and younger stages $(1.2,1.4)$ of the same species of Coleoidea. 1.1-2. Gladii of Onykia robusta (Verrill, 1876). Gladius of younger stage much stouter than that of older stage. Redrawn after Tsuchiya and Okutani (1991, figures 18, 19). 1.3-4. Gladii of Pholidoteuthis massyae (Pfeffer, 1912), exhibiting shape differences between the different stages. Redrawn after O'Shea et al. (2007, figures 36, 37).

ferences demands for the availability of several specimens representing consecutive developmental stages (= semaphoronts). The approach to reconstruct the ontogeny of coleoids based on a series of individuals has been applied for details of the soft parts of extant species (O'Shea et al., 2007). For such approaches small-sized specimens are of importance, especially for accessing information on the earliest post-hatching phase, the paralarva. Early post-hatching specimens of fossil cephalopods are relatively rare (e.g., Mapes et al., 2007; Mapes and Nützel, 2009). No speci- 
men of a fossil coleoid being small enough to possibly represent a paralarva has been described to date.

We report here a single specimen from the lithographic limestones of Solnhofen (Upper Jurassic, southern Germany) that is supposed to represent an early developmental stage of a coleoid, possibly a paralarva. To emphasize the importance of this find we discuss the different approaches of reconstructing developmental sequences, either from growth marks of a single mature specimen or based on a series of semaphoronts.

\section{MATERIAL AND METHODS}

\section{Material}

The single specimen described here was found by Michael Fecke, Langenberg, in the hobby quarry Blumenberg near Eichstätt, which belongs to the area of the Solnhofen Lithographic Limestones (Upper Jurassic, Lower Tithonian, lower Hybonotum zone, Riedense subzone; Schweigert, 2007). The specimen is preserved as part only, a counterpart is not available. It is tiny (ca. $3 \mathrm{~mm}$ ), but is preserved with substance differing from the surrounding matrix as its autofluorescence capabilities suggest, possibly consisting of calcium phosphate (Haug et al., 2009). The fossil displays a recognizable relief. It is now part of the collection of the Staatliches Museum für Naturkunde Stuttgart under SMNS 67904b. Also preserved on the same slab is a small specimen of a mantis shrimp, tentatively assigned to ?Sculda pusilla (SMNS 67904a; cf. Haug et al., 2010).

\section{Methods}

Due to the small size of the specimen it was necessary to apply higher magnification imaging. A simple macrograph was recorded under standard North-West lighting. Under the same setting a stereo image was recorded. Additionally, the specimen was documented under a Zeiss Axioskop 2 fluorescence microscope under green light (546 $\mathrm{nm})$. Images were processed following the protocol of composite fluorescence imaging (Haug et al., 2008; Haug et al., 2009; Kerp and Bomfleur, 2011) using CombineZM/ZP, Microsoft Image Composite Editor or Adobe Photoshop CS3. Image processing, such as optimizing contrast, was performed in Adobe Photoshop CS3 and GIMP. A simplified 3D model of the here described specimen was created in Blender. For comparison, also a 3D model of a trachyteuthidid was remodeled after Fuchs et al.
(2007). Drawings from the literature were redrawn using Adobe Illustrator CS3 and Inkscape.

\section{RESULTS}

\section{Description of the Specimen (Figure 2.1-3)}

We use the terminology as applied by Fuchs et al. (2009) for fossil gladii. The specimen is relatively flat, but slightly more elevated in the median region (Figure 2.1, 2.3). Based on this elevation the specimen is most likely seen in dorsal view. The outline is more or less oval to leaf-shaped. Its maximal length is $3 \mathrm{~mm}$. On the widest part it measures $1.6 \mathrm{~mm}$. The area preserved in this specimen is interpreted as representing mainly the median field of a gladius. Remains of the hyperbolar zone/lateral fields can still be detected under fluorescence settings (Figure 2.2), but are too weakly preserved to infer the outline. Thus, the original maximal width of the specimen is not accessible. Whether the weak preservation of the lateral fields reflects original structural conditions or is a preservational artifact cannot be determined. The midline of the median field is marked by a prominent keel. The keel is very narrow (ca. $60 \mu \mathrm{m}$ ) along the anterior part of ca. $2 \mathrm{~mm}$ length. Then the keel widens to a pear-shaped structure towards the apex with a maximum width of $0.45 \mathrm{~mm}$. Closer to the apex the keel becomes more slender again, measuring about $0.13 \mathrm{~mm}$ in width. A kite-shaped area in the anterior $40 \%$ (median) to $30 \%$ (lateral) of the entire gladius length bears a surface ornamentation. Under fluorescence this ornament appears like a reticulate pattern (Figure 2.2). In combination with the stereo image it becomes clear that this pattern is in fact a cluster of small pits (Figure 2.3). The diameter of the pits ranges from 20-70 $\mu \mathrm{m}$.

\section{DISCUSSION}

\section{Cephalopod Affinities}

The here described specimen is interpreted as a small fragmentarily preserved gladius of a coleoid cephalopod (Figure 3.1). Its shape is relatively stout, yet early developmental stages of cephalopods are usually less elongate than they are as adults. This could well be reflected also by gladius shape and, thus, can explain the relative stoutness of the specimen. Unfortunately, no literature is available on gladius shape development from the earliest developmental phase onwards, but only beginning with juvenile stages of already several centimeters mantle length (which more or less equals gladius length; Tsuchiya and Okutani, 

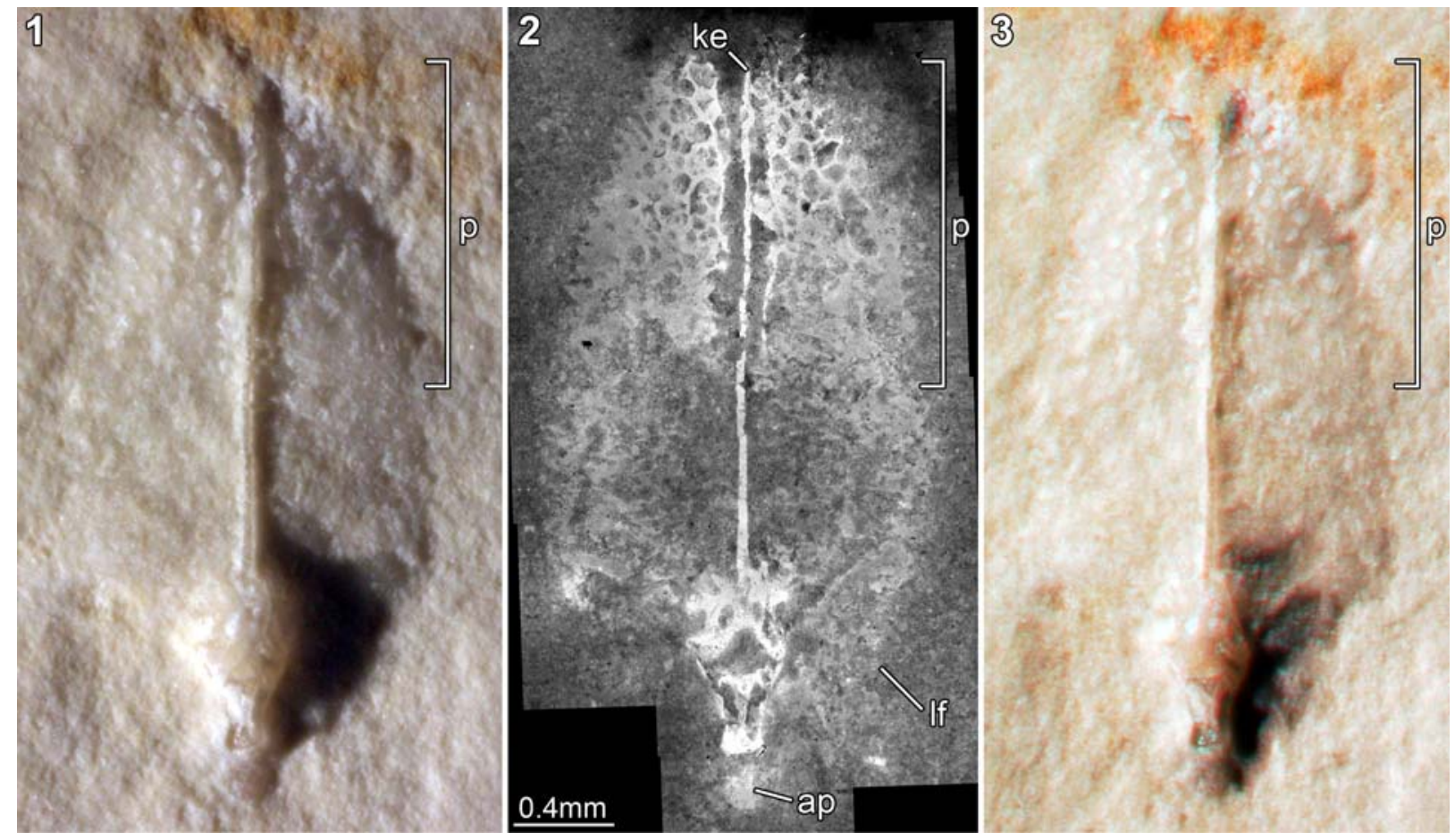

FIGURE 2. The supposed gladius of a fossil cephalopod paralarva (SMNS 67904b), documented with different methods. 2.1. Macrograph under North-West lighting. 2.2. Autofluorescence micrograph. Note the lateral field and the pits, forming a reticulate pattern. 2.3. Red-cyan stereo image with pronounced keel and pits; use red-cyan glasses to view. Abbreviations: $a p=a p e x ; k e=k e e l ;$ If $=$ lateral field; $p=$ pitted area.

1991; O'Shea et al., 2007). Here, the gladii of younger stages can clearly also be stouter than those of conspecific older stages (cf. Figure 1.1 vs. 1.2 , see also Figure 1.3 vs. 1.4).

The fact that the lateral fields are only very fragmentarily preserved makes the definite interpretation of the here described specimen even more difficult. Yet, other morphological aspects of the new fossil can be compared with gladii of other fossil specimens. The presence of a pronounced keel resembles the morphology of other fossil gladii, for example, those of certain morphotypes of Trachyteuthis Meyer, 1846 (Fuchs et al., 2007, figure 2C), Teudopsis Eudes-Deslongchamps, 1835 (Fuchs et al., 2009, figure 9) or closely related forms (Fuchs, 2009, figure 2). The keeled type of Trachyteuthis resembles the here described specimen in another aspect: A kite-shaped anterior region bears a typical surface ornament (Figure 3.2). Yet, this area is described as granulated in Trachyteuthis, i.e., as bearing small humps. This is in contrast to the here described specimen, in which the ornament appears to be made of pits. This could be seen as an indication that we see the specimen from the ventral side, and the pits would be humps seen from the inner side. Yet, this interpretation is not in concordance with the convex structure of the keel and the elevation of the entire gladius. Currently, we have no explanation for this difference.

Additionally, the surface ornament in Trachyteuthis extends onto the keel, which is not the case in the here described specimen. The keel seen in this specimen is too narrow to bear ornament of similar size to the surrounding area. An ornament with comparably sized elements can only develop later when the keel has become broader. Still, as in both cases an anterior kite-shaped area is covered by an ornament with small-sized elements, both types of ornamentation could mark a corresponding area.

A structure that is more difficult to interpret is the pear-shaped structure at the posterior end. No comparable structure could be found on any other fossil gladius in the literature. In recent cephalopods, some representatives of Oegopsida show a blunt tip of the gladius in the early stages of development (e.g., Vecchione et al., 2001, figure 11), but no fossil oegopsids are currently known from the Jurassic (Kröger et al., 2011). 


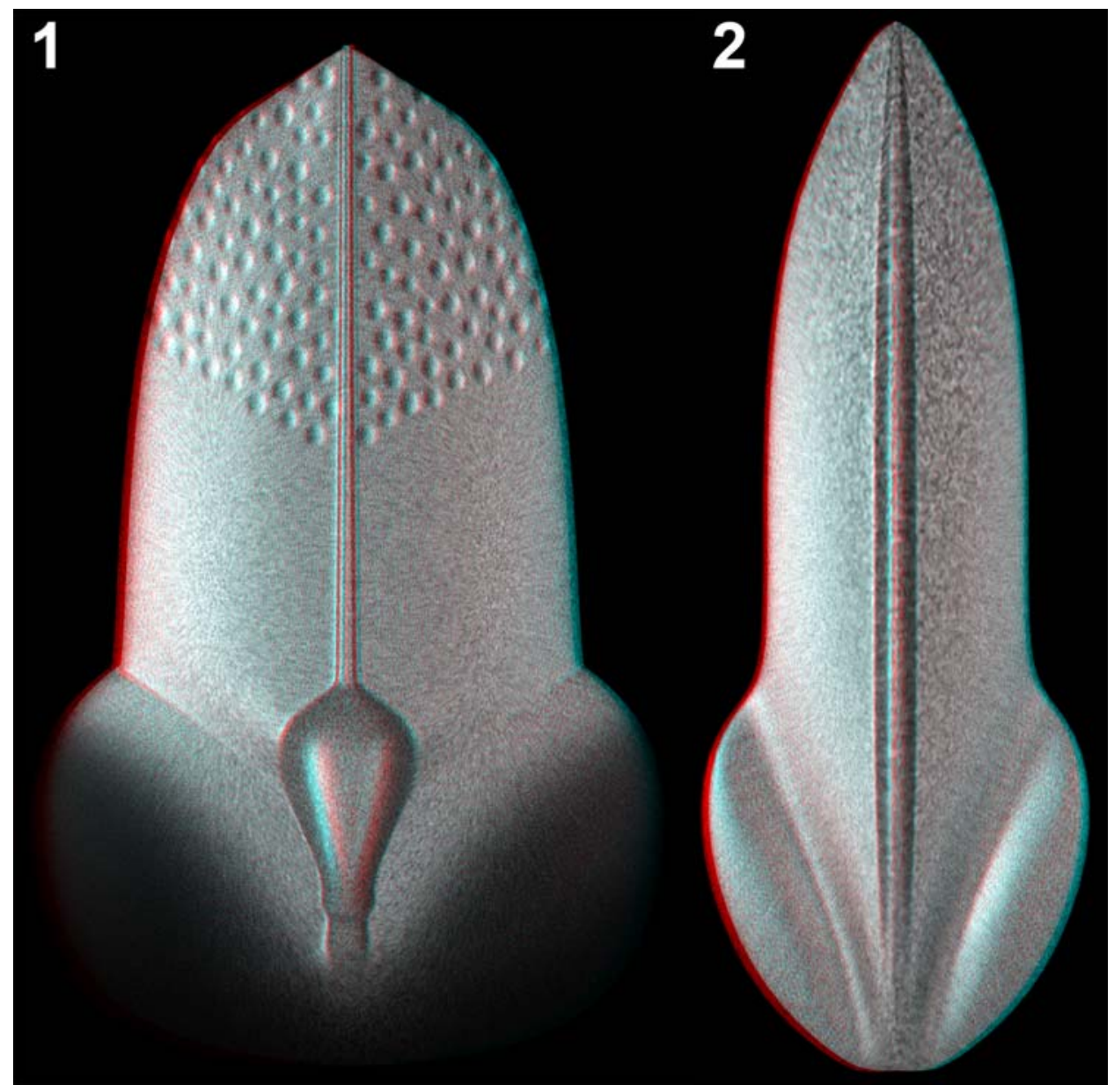

FIGURE 3. 3D models of the gladii of the supposed new paralarva and its posssible adult (red-cyan stereo images). Images not to scale to show the different length-width ratios. 3.1. Gladius of the possible paralarva presented in this paper. The faint areas represent the only partially preserved lateral fields. 3.2. Gladius of the keeled type of Trachyteuthis with morphological similarities to that of the possible paralarva.

The structure could also represent a crystallised stomach with its content. Position and size would be in concordance with this interpretation.

In summary, the interpretation of the specimen representing a coleoid gladius (but with parts of the stomach?) is seen as plausible. The discernible structures can be interpreted as corresponding to those on gladii of other Mesozoic coleoids. Differences in shape, e.g., the stoutness of the specimen, can be explained by the early developmental stage of the specimen.

A possible adult stage of the specimen could be, due to similarities mentioned above, the keeled type of Trachytheuthis (Fuchs et al., 2007, figure 2C; Figure 3.2). Yet, as we know only little about changes of gladius shape from early ontogenetic stages to the adult, especially of fossil cephalopods, this must also currently remain an assumption. Additionally, there are other possible candidates for a conspecific adult to the new specimen. As mentioned before, Teudopsis shows certain similarities, but other forms that share the principle shape as well as a pronounced median keel would be possible (cf. Fuchs, 2009, figure 2). Even species such as Muensterella scutellaris (Münster, 1842) have about the same shape as the here described specimen and the pronounced median keel (Fuchs et al., 2003). The lateral fields of $M$. scutellaris are significantly larger than that of Trachyteuthis or Teudopsis. However, this character cannot be used to make the one or other assignment for the specimen more likely, as the lateral fields are only very poorly preserved in the here described specimen. Lastly, there are modern examples of tiny adult cephalopods (Lu et al., 1992; Boletzky, 1995). Thus, it cannot be excluded that the specimen could in principle represent an adult of a new dwarf species. A more definite 
assignment demands for a more or less complete series of specimens representing a growth series.

\section{Paralarval Status}

The definition of the term paralarva is coupled to ecological and behavioral factors (Young and Harmann, 1988). The lack of precise morphological criteria makes it difficult to apply this definition to fossil representatives of Cephalopoda as the necessary information is usually not available. As far as we know the term has not been used for fossil cephalopods yet, probably because of these aspects of the definition. The other part of the definition is coupled to changes in the growth pattern. Such a criterion is principally applicable to fossils, but it demands for a (more or less complete) growth sequence, and in early ontogenetic stages the growth lines might be vague and difficult to interpret (Boyle and Rodhouse, 2005). Thus, for the moment it is not possible to judge with certainty whether the here described specimen indeed represents a paralarva in the strict sense. Yet, its small size ( $3 \mathrm{~mm}$ mantle length) and the fact that the specimen differs morphologically from any possible adult make it possible that it is indeed a paralarva, although as stated above also the possibility that the specimen represents an adult of a dwarf species cannot be excluded.

The single specimen, although fragmented, should draw our attention to the fact that such tiny specimens are available in the fossil record, especially in the lithographic limestones of southern Germany. These deposits have already yielded significant larval material of arthropods (summary in Haug et al., 2011), including tiny crustaceans comparable in size to the small gladius described here, as well as clearly planktic organisms (as are paralarvae during the day).

Knowing the ontogeny of an animal offers key insights into the biology of this organism and can provide new clues about its phylogenetic position and evolution. This is true for extant as well as fossil organisms, also for molluscs (e.g., Nützel et al., 2007). The possible paralarva presented here should encourage further search for such small specimens to improve our knowledge on the early phase of development of fossil coleoid cephalopods. The alternative interpretation of the specimens as a possible adult of a small-sized species would indicate an early niche differentiation within the coleoids and also add new insights into the early diversification of the group.

\section{CONCLUSIONS}

The discovery of the here described specimen indicates that early ontogenetic stages (or tiny adults) of coleoids can be found fossilized in the limestones of Solnhofen, just like other components of the zooplankton. The interpretation that the new specimen represents a paralarva, possibly of a trachyteuthidid or a closely related cephalopod, is seen as plausible and possibly opens a new glimpse on the early life history of fossil coleoid cephalopods.

\section{ACKNOWLEDGEMENTS}

We would like to thank M. Fecke, Langenberg, who has repeatedly provided interesting specimens for our research, including the here described specimen. G. Schweigert, Staatliches Museum für Naturkunde Stuttgart, is thanked for curating the specimen and for discussion. Furthermore, we are grateful to S. Liebau, University of Ulm, for his long-lasting support and help with the Axioskop 2. D. Fuchs, Freie Universität Berlin, and an anonymous reviewer are thanked for helpful suggestions on an earlier draft of the manuscript. This work would not have been possible without many freely available software packages. Therefore, we thank all people that are involved in projects providing such programs, such as OpenOffice, CombineZM/ZP, Microscoft Image Composite Editor, Gimp, Inkscape and Blender. J.T. Haug was kindly supported by the Alexander von Humboldt $(\mathrm{AvH})$ Foundation with a Feodor Lynen Research Fellowship for postdoctoral researchers and is currently supported by $\mathrm{AvH}$ with a Feodor Lynen return fellowship. I. Kruta is currently supported by a Gaylord Donnelley Fellowship. C. Haug is funded by the Germany Academic Exchange Service (DAAD) with a return fellowship. We also express our sincere thanks to our hosts D.E.G. Briggs, Yale University and Yale Peabody Museum, and S. Harzsch, University of Greifswald.

\section{REFERENCES}

Boletzky, S.v. 1995. The systematic position of the Sepiolidae (Mollusca: Cephalopoda). Bulletin de l'Institut Océanographique, Monaco, NS 16:99-104.

Boletzky, S.v. 2003. Biology of early life stages in cephalopod molluscs. Advances in Marine Biology, 44:143203.

Boyle, P.R. and Rodhouse, P. 2005. Cephalopods: Ecology and Fisheries. Blackwell Science, Oxford. 
Eudes-Deslongchamps, M. 1835. Mémoire sur les Teudopsides, animaux fossiles, voisins des calmars. Mémoires de la Société Linnéenne de Normandie, 5:68-78.

Fuchs, D. 2009. Octobrachia - a diphyletic taxon? Berliner paläobiologische Abhandlungen, 10:181-192.

Fuchs, D., Bracchi, G., and Weis, R. 2009. New octopods (Cephalopoda: Coleoidea) from the Late Cretaceous (Upper Cenomanian) of Hâkel and Hâdjoula, Lebanon. Palaeontology, 52:65-81.

Fuchs, D., Engeser, T., and Keupp, H. 2007. Gladius shape variation in coleoid cephalopod Trachyteuthis from the Upper Jurassic Nusplingen and Solnhofen Plattenkalks. Acta Palaeontologica Polonica,52:575589.

Fuchs, D., Keupp, H. and Engeser, T. 2003. New records of soft parts of Muensterella scutellaris Muenster, 1842 (coleoidea) from the late Jurassic plattenkalks of Eichstätt and their significance for octobrachian relationships. Berliner Paläobiologische Abhandlungen, 3:101-111.

Haimovici, M., Piatkowski, U., and Aguir dos Santos, R. 2002. Cephalopod paralarvae around tropical seamounts and oceanic islands off the North-Eastern coast of Brazil. Bulletin of Marine Science, 71:313330.

Haug, C., Haug, J.T., Waloszek, D., Maas, A., Frattigiani, R., and Liebau, S. 2009. New methods to document fossils from lithographic limestones of southern Germany and Lebanon. Palaeontologia Electronica, 12(3); 6T; 12p.

Haug, J.T., Haug, C., and Ehrlich, M. 2008. First fossil stomatopod larva (Arthropoda: Crustacea) and a new way of documenting Solnhofen fossils (Upper Jurassic, Southern Germany). Palaeodiversity, 1:103-109.

Haug, J.T., Haug, C., Waloszek, D., and Schweigert, G. 2011. The importance of lithographic limestones for revealing ontogenies in fossil crustaceans. Swiss Journal of Geosciences, 104, Supplement 1:S85S98.

Haug, J.T., Haug, C., Maas, A., Kutschera, V., and Waloszek, D. 2010. Evolution of mantis shrimps (Stomatopoda, Malacostraca) in the light of new Mesozoic fossils. BMC Evolutionary Biology, 10, art. $290,17 \mathrm{p}$.

Hickman, C.S. 1999. Larvae in invertebrate development and evolution, p. 21-59. In Hall, B.K. and Wake, M.H. (eds.), The Origin and Evolution of Larval Forms. Academic Press, San Diego, London.

Kerp, H. and Bomfleur, B. 2011. Photography of plant fossils - New techniques, old tricks. Review of Palaeobotany and Palynology, 166:117-151.

Kröger, B., Vinther, J., and Fuchs, D. 2011. Cephalopod origin and evolution: A congruent picture emerging from fossils, development and molecules. BioEssays, 33:602-613.
Kruta, I., Landman, N., Rouget, I., Cecca, F., and Tafforeau, P. 2011. The role of ammonites in the Mesozoic marine food web revealed by jaw preservation. Science, 331(6013):70-72.

Lu, C.C., Guerra, Á., Palumbo, F., and Summers, W.C. 1992. Family accounts: order Sepioidea Naef, 1916, p. 21-36. In Sweeney, M.J., Roper, C.F.E., Mangold, K.M., Clarke, M.R., and Boletzky, S.v. (eds.), "Larval“" and juvenile cephalopods: a manual for their identification. Smithsonian Contributions to Zoology, 513. Smithsonian Institution, Washington, DC.

Mapes, R.H. and Nützel, A. 2009. Late Palaeozoic mollusc reproduction: cephalopod egg-laying behavior and gastropod larval palaeobiology. Lethaia, 42:341356.

Mapes, R.H., Niko, S., Fryda, J., and Nützel, A. 2007. A newly hatched coiled nautiloid from the Permian of Italy. Journal of Paleontology, 81:1118-1121.

Meyer, H. v. 1846. Mitteilungen an Prof. Bronn gerichtet. Neues Jahrbuch Mineralogischer, Geognostischer und Geologischer Petrefactenkunde, 1846:596-599.

Minelli, A. 2003. The Development of Animal Form: Ontogeny, Morphology, and Evolution. Cambridge University Press, Cambridge.

Münster, G.z. 1842. Ueber einige neue fossile schalenlose Cephalopoden und eine neue Gattung Ringelwürmer (Anneliden). Beiträge zur Petrefaktenkunde, 5:95-99.

Nützel, A., Fryda, J., Yancey, T.E., and Anderson, J.R. 2007. Larval shells of Late Palaeozoic naticopsid gastropods (Neritopsoidea: Neritimorpha) with a discussion of the early neritimorph evolution. Paläontologische Zeitschrift, 81:213-228.

O'Shea, S., Jackson, G., and Bolstad, K.S. 2007. The nomenclatural status, ontogeny and morphology of Pholidothehthis massyae (Pfeffer, 1912) new comb (Cephalopoda: Pholidoteuthidae). Reviews in Fish Biology and Fisheries, 17:425-435.

Perez, J.A.A. and O'Dor, R.K. 2000. Critical transitions in early life histories of short-finned squid, Illex illecebosus as reconstructed from gladius growth. Journal of the Marine Biological Association of the United Kingdom, 80:509-514.

Pfeffer, G. 1912. Die Cephalopoden der Plankton-Expedition, p. 1-815. In Hensen, V.A.C. (ed.), Ergebnisse der Plankton-Expedition der Humboldt-Stiftung, 2(11).

Schweigert, G. 2007. Ammonite biostratigraphy as a tool for dating Upper Jurassic lithographic limestones from South Germany - first results and open questions. Neues Jahrbuch für Geologie und Paläontologie, Abhandlungen, 245:117-125.

Tsuchiya, K. and Okutani, T. 1991. Growth stages of Moroteuthis robusta (Verrill, 1881) with the re-evaluation of the genus. Bulletin of Marine Science, 49:137147. 
Tsuchiya, K., Nagasawa, T., and Kasahara S. 1991. Cephalopod paralarvae (Excluding Ommastrephidae) collected from Western Japan Sea and Northern Sector of the East China Sea during 1987-1988: preliminary classification and distribution. Bulletin of the Japan Sea National Fisheries Research Institute, 41:43-71.

Vecchione M., Robison, B.H., and Roper, C.F.E. 1992. A tale of two species: tail morphology in paralarval Chiroteuthis (Cephalopoda: Chiroteuthidae). Proceedings of the Biological Society of Washington, 105:683-692.

Vecchione, M., Roper, C.F.E., Sweeny, M.J., and Lu, C.C. 2001. Distribution, relative abundance and developmental morphology of paralarval cephalopods in the Western North Atlantic Ocean. National Oceanic and Atmospheric Administration Technical Report National Marine Fisheries Service, 152:1-54.
Verrill, A.E. 1876. Note on gigantic cephalopods: A correction. American Journal of Science and Arts, 12:236-237.

Weitschat, W. 1986. Phosphatisierte Ammonoideen aus der Mitteleren Trias von Central-Spitzbergen. Mitteilungen aus dem Geologisch-Paläontologischen Institut der Universität Hamburg, 61:249-279.

Young, C.M. 2002. A brief history and some fundamentals, p. 1-19. In Young, C.M. (ed.), Atlas of Marine Invertebrate Larvae. Academic Press, San Diego, London.

Young, R.E. and Harman, R.F. 1988. "Larva", "paralarva" and "subadult" in cephalopod terminology. Malacologia, 29:201-207. 